\title{
A Facile Strategy for the Growth of an Anodic Oxidation Film of the Ti13Nb13Zr Alloy Driven by Residual Stress
}

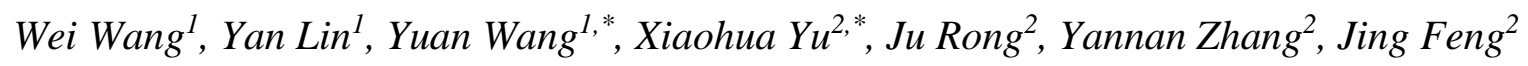 \\ ${ }^{1}$ School of Machinery and Manufacturing Engineering, Southwest Forestry University, Kunming \\ 650224,China \\ ${ }^{2}$ National Engineering Research Center of Solid Waste Resource, Kunming University of Science and \\ Technology, Kunming 650093, China \\ *E-mail: wyuan88@126.com, xiaohua_y@163.com
}

doi: $10.20964 / 2019.03 .52$

Received: 9 October 2018/ Accepted: 10 January 2019 / Published: 7 February 2019

\begin{abstract}
Anodizing offers a promising solution to improve the corrosion resistance of $\mathrm{Ti}$ and $\mathrm{Ti}$ alloys; however, the development of dense and thick anodic oxidation films remains an important scientific problem. Herein, we report a novel and facile strategy for the growth of an anodic oxidation film of the Ti13Nb13Zr alloy driven by residual stress. Under residual stress conditions, the gradient defect film on the Ti13Nb13Zr alloy surface is prepared. The change is coupled to an increase in surface defects and the surface Gibbs free energy, providing structural disorder and boosting the intrinsic activity of the Ti13Nb13Zr alloy surface, which strongly enhances the compactness, thickness and corrosion resistance of the Ti13Nb13Zr surface anodic oxide film. The thickness of the oxide layer increases up to $47.1 \%$ under the best residual stress condition. Furthermore, the donor density reduces by $500 \%$, the self-corrosion potential increases by $30.4 \%$ and the self-corrosion current density decreases by $64.2 \%$.
\end{abstract}

Keywords:Ti13Nb13Zr alloy; Shot peening; Residual compressive stress; Gibbs free energy; Corrosion resistance

\section{FULL TEXT}

(C) 2019 The Authors. Published by ESG (www.electrochemsci.org). This article is an open access article distributed under the terms and conditions of the Creative Commons Attribution license (http://creativecommons.org/licenses/by/4.0/). 